\title{
The orientation dependence of the strength of ice single crystals
}

\author{
Y. L. Trickett, I. Baker, P. M. S. Pradhan \\ Thayer School of Engineering, Dartmouth College, Hanover, New Hampshire 03755, U.S.A.
}

\begin{abstract}
Single crystals with a wide variety of orientations were cut from large pucks of laboratory-grown ice. Constant-strain-rate compression tests were performed on the crystals either at an axial strain rate of $1 \times 10^{-5} \mathrm{~s}^{-1}$ at $-20^{\circ} \mathrm{C}$ or at axial strain rates from $1 \times 10^{-6} \mathrm{~s}$ to $1 \times 10^{-4} \mathrm{~s}^{-1}$ at $-10^{\circ} \mathrm{C}$. In agreement with previous studies of ice flow, the compression tests showed a linearly rising stress with increasing strain, followed by a sharply declining stress after reaching a peak. With further strain, the sharp decline in stress slowed and the flow stress approached a plateau that was only weakly dependent on strain. For all crystallographic orientations, it was found that Schmid's (critical resolved shear stress) law was obeyed by the peak stress. Slip lines clearly showed that basal slip was the deformation mode.
\end{abstract}

\section{INTRODUCTION}

The mechanical properties of pure-ice single crystals have been determined by a number of workers (i.e. Griggs and Coles, 1954; Steinemann, 1954; Kamb, 1961; Higashi and others, 1964, 1965; Readey and Kingery, 1964; Jones and Glen, 1968, 1969; Muguruma, 1969; Nakamura and Jones, 1973; Jones and Brunet, 1978). Although the wide variety of testing conditions used makes it difficult to compare their results, several factors, including temperature, strain rate, initial dislocation density, previous straining history, surface condition and orientation have been shown to affect the mechanical behavior of ice single crystals. This paper is concerned with the effect of orientation on the strength of ice single crystals.

If yielding in a crystal depends only on when the applied stress, $\sigma_{\mathrm{a}}$, resolved in the slip direction on the slip plane reaches a critical value, i.e. the critical resolved shear stress (CRSS), $\tau^{\mathrm{S}}$, then Schmid's law applies, i.e.

$$
\tau^{\mathrm{S}}=\sigma_{\mathrm{a}} \cos \theta \cos \lambda
$$

where $\theta$ is the angle between the loading direction and the normal to the slip plane, and $\lambda$ is the angle between the loading direction and the slip direction. The term $\cos \theta \cos \lambda$ is often given the symbol, $m$, and referred to as the Schmid factor. $\tau^{\mathrm{S}}$ is a material property, which depends on the defect structure and the previous strain history. When yielding is controlled by a Peierls stress, the magnitude of $\tau^{\mathrm{S}}$ may depend on other components of the applied stress, such as the stress normal to the slip plane, which affect the dislocation core structure. In such cases, the use of Schmid's law is inappropriate.

The structure of ice $I_{h}$ consists of (0001) layers of water molecules stacked in the sequence AABBAABBAA. In principle, dislocations can glide either between widely spaced $\mathrm{AA}$ or BB planes (shuffle set) or between closely spaced AB or BA planes (glide set). Although it is still uncertain on which type of basal planes dislocations move, the perfect Burgers vectors, $\mathbf{b}$, in both cases are $a / 3\langle 11 \overline{2} 0\rangle$.
Kamb (1961) concluded that, in ice single crystals, slip occurs in the direction of the maximum resolved shear stress acting across (0001), irrespective of the orientation relationship between $\mathbf{b}$ and $\sigma_{\mathrm{a}}$. Thus, the resolved shear stress on the basal plane was determined by Nakamura and Jones (1973) and Jones and Brunet (1978) from

$$
\tau=\sigma_{\mathrm{a}} \cos \theta \sin \theta .
$$

Most mechanical tests on ice crystals have been performed with the $c$ axis around $45^{\circ}$ to the loading direction. In other words, the effects of different orientations were not readily observable. However, Brown and Kawamura (1991) compressed sea-ice single crystals with $c$-axis orientations of $45^{\circ}$ and $66^{\circ}$ to the loading direction at $-11^{\circ} \mathrm{C}$ and a constant strain rate of $4 \times 10^{-5} \mathrm{~s}^{-1}$. They found peak stresses of 0.65 and 1.15 MPa, respectively, with corresponding steady-state flow (plateau) stresses of 0.31 and $0.45 \mathrm{MPa}$. As expected, the less favorable orientation for basal slip needed a larger stress for yielding and subsequent flow at the same axial strain rate. The value of $\tau^{\mathrm{S}}$, calculated from Equation (1), at $66^{\circ}$ was $0.37 \mathrm{MPa}$ which was $32 \%$ higher than that $(0.28 \mathrm{MPa})$ at $45^{\circ}$, while the subsequent resolved flow stresses were always slightly higher for the " $66^{\circ}$-oriented" crystals. The difference in $\tau^{\mathrm{S}}$ may have been because stresses other than the resolved shear stress affect basal slip, or because the shear strain rates on the basal slip plane were different in the two tests.

In this paper we set out to answer the question, how does the crystallographic orientation affect the flow of ice single crystals? In other words, is Schmid's law applicable to ice?

\section{EXPERIMENTAL}

A Nalgene tank with a $19 \mathrm{~L}$ capacity, filled with distilled water, was placed in a cold room at $1^{\circ} \mathrm{C}$ for 1 day to equilibrate the water temperature before it was moved into a $-4^{\circ} \mathrm{C}$ freezer for ice growth. The sides and bottom of the tank were wrapped with Armaflex for insulation so that the ice grew only from the top downwards. Generally, it took 7 days to 
grow an ice puck about $13 \mathrm{~cm}$ thick. During the ice growth the tank was left uncovered. Using this method, columnar ice with a large grain-size was obtained. The long axis of the columns was along the growth direction, while the $c$ axis was randomly oriented in the plane perpendicular to the growth direction.

After the ice puck was removed from the tank, the top and bottom were removed using a chainsaw. A band-saw was then employed to make the remaining ice rectangular, and the rough surfaces were shaved with a razor blade. The ice was stored in a plastic bag in a $-10^{\circ} \mathrm{C}$ freezer for later use.

Higashi and others (1965) first observed that the steadystate strain rate in bending creep tests was affected by the surface condition of ice single crystals. This effect was further studied in constant-strain-rate compression tests by Muguruma (1969). For example, at $-10^{\circ} \mathrm{C}$ and a constant strain rate of $4.2 \times 10^{-5} \mathrm{~s}^{-1}$, the peak stress for chemically polished specimens was approximately double that for mechanically polished specimens, while the latter was more than twice that for crystals containing sub-boundaries. The variation in the shape of stress-strain curves was considered to be due to differences in the dislocation density of crystals. The imperfect surface produced by mechanical polishing and the sub-boundaries acted as sources of dislocations. In order to avoid the effects of surface conditions on the mechanical behavior of ice single crystals, all specimens used here were prepared in exactly the same way. Further sample preparation utilized the following steps:

(1) Polarized illumination was used to examine the grainsize in the ice bulk. Under the polarized light, each grain showed different contrast due to different orientations (Hobbs, 1974). Several large grains were marked and then cut out using the band-saw. After cutting, the rough surfaces were shaved with a razor blade.

(2) The orientation of each ice single crystal was determined using the etch-pit technique to $\pm 2^{\circ}$ (Higuchi, 1958). After the $c$ axis and $a$ axes were identified according to the shapes of etch pits, polarized light was employed to further confirm the $c$ axis to $\pm 1^{\circ}$.

(3) Knowing the orientation of the ice single crystal, the specimen was cut so that the basal plane (0001), marked by a hexagon in Figure 1, was tilted an angle $\theta$ from the top surface, with $\{11 \overline{2} 0\}$ planes on the side. The $[11 \overline{2} 0]$ and $[10 \overline{1} 0]$ directions are also indicated in Figure 1 . The values of $\theta$ were chosen to be in the range $3-70^{\circ}$, with several specimens tested at some orientations.

(4) A horizontal-milling machine housed in a cold room was used to smooth the surfaces of specimens to their final dimensions of about $20 \mathrm{~mm} \times 25 \mathrm{~mm} \times 60 \mathrm{~mm}$.

(5) The dimensions of all the specimens were measured using a caliper ruler, and their orientations were again determined under polarized light to $\pm 1^{\circ}$.

A series of constant-strain-rate compressive tests was performed on these ice single crystals as a function of orientation at $-20 \pm 0.5^{\circ} \mathrm{C}$ at a constant axial strain rate of $1 \times 10^{-5} \mathrm{~s}^{-1}$ using a servohydraulic Material Testing Systems device housed in a cold room. A limited number of compression tests were also performed at $-10 \pm 0.5^{\circ} \mathrm{C}$ for crystals with orientations where $\theta=5^{\circ} \pm 1^{\circ}$ at strain rates from $1 \times 10^{-6} \mathrm{~s}^{-1}$ to $1 \times 10^{-4} \mathrm{~s}^{-1}$.

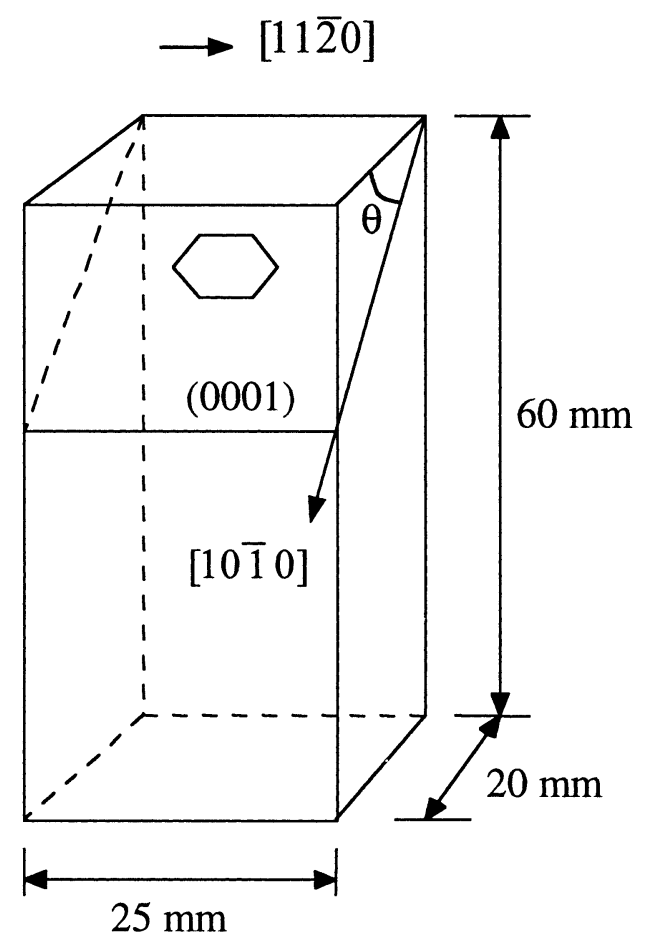

Fig. 1. Schematic showing the dimensions and orientation of the pure-ice single crystals. The plane with the hexagon is the basal plane. The basal plane was tilted $\theta$ from the top surface. $[11 \overline{2} 0]$ and $[10 \overline{10}]$ axes are also indicated.

\section{RESULTS AND DISGUSSION}

Typical engineering stress-strain curves at $-20^{\circ} \mathrm{C}$ for various orientations obtained at a constant axial strain rate of $1 \times 10^{-5} \mathrm{~s}^{-1}$ are shown in Figure 2. Except for crystals with $\theta=3^{\circ}$ and $5^{\circ}$, their shape is generally similar, i.e. the stress rises linearly to a peak stress after which it falls rapidly and then more slowly towards a plateau. The specimen with $\theta=$ $3^{\circ}$ fractured immediately after the peak stress, and the test at $\theta=5^{\circ}$ was stopped at an axial strain of about $2 \%$ (when the stress was close to zero). All other tests were continued up to an axial strain of about $5 \%$.

Figure 3 shows the peak stress (yield stress), obtained from $\theta=3-70^{\circ}$, plotted as a function of the Schmid factor, $\cos \lambda \cos \theta$. The peak stress depends on the initial mobile dislocation density. Here it is assumed that all the specimens had similar dislocation densities since, as noted earlier, they were made in exactly the same way. The reproducibility of the results at a particular orientation tended to confirm this (see Fig. 3).

Although the peak stress values in Figure 3 were obtained at the same axial strain rate, the shear strain rate on the basal plane, $\dot{\gamma}$, varied considerably as $\theta$ varied from $3^{\circ}$ to $70^{\circ}$. In order to determine whether Schmid's law is obeyed in ice it is necessary to compare the CRSS values at different values of $\cos \theta \cos \lambda$ at the same shear strain rate. Thus, $\dot{\gamma}$ was calculated by dividing the shear strain on the basal slip plane, $\gamma$, by the time. $\gamma$ is given by (Schmid and Boas, 1950; Reid, 1973)

$$
\gamma=\left\{-\cos \theta_{0}+\left[\left(\ell_{0} / L\right)^{2}-\sin ^{2} \theta_{0}\right]^{1 / 2}\right\} / \cos \lambda_{0},
$$

where $\ell_{0}$ is the original length of the specimen, $L$ is the deformed length of the specimen, $\lambda_{0}$ is the initial value of $\lambda$ (at the start of the test) and $\theta_{0}$ is the initial value of $\theta$. Figure 4 is a plot of the calculated CRSS normalized to a constant shear 


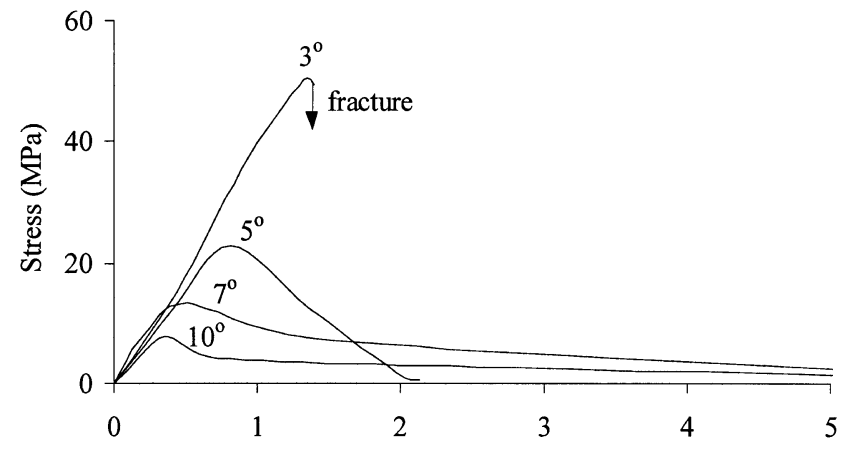

$\mathbf{a}$

Strain (\%)
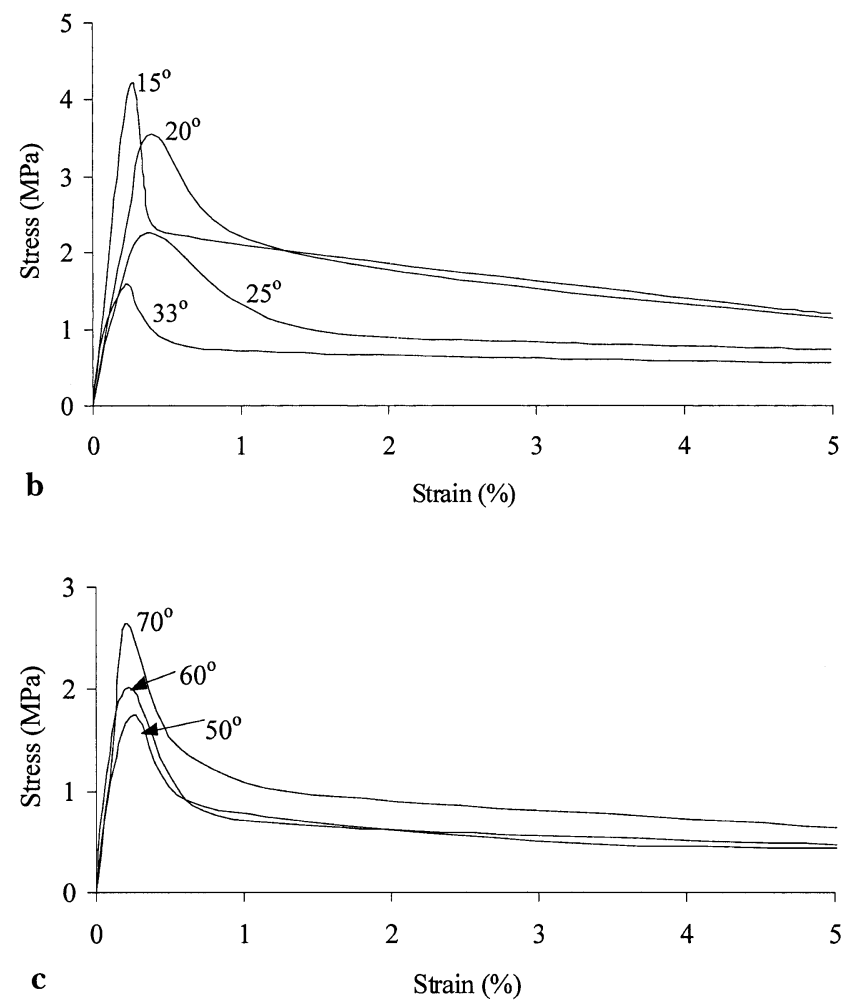

Fig. 2. Typical engineering stress-strain curves of pure-ice single crystals at an axial strain rate of $1.0 \times 10^{-5} \mathrm{~s}^{-1}$ and $-20^{\circ} \mathrm{C}$, with orientations: ( a) $\theta=3-10^{\circ}$; (b) $\theta=15-33^{\circ}$; and (c) $\theta=$ $50-70^{\circ}$.

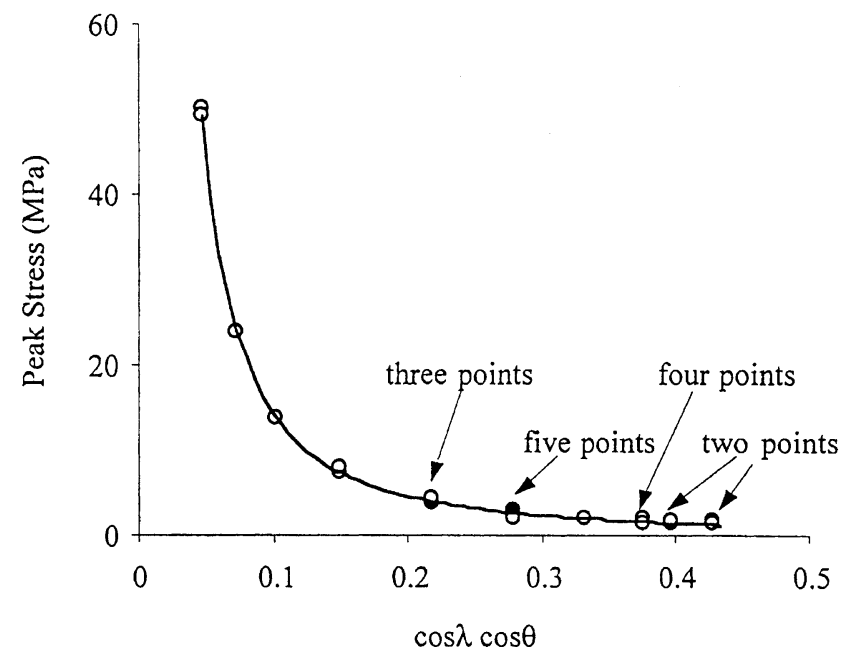

Fig. 3. Peak stress (at $\theta=3-70^{\circ}$ ) vs Schmid factor $(\cos \lambda \cos \theta)$ at a constant axial strain rate of $1.0 \times 10^{-5} \mathrm{~s}^{-1}$. When more than one test was performed at a particular orientation and the data points overlap, the number of tests is indicated.

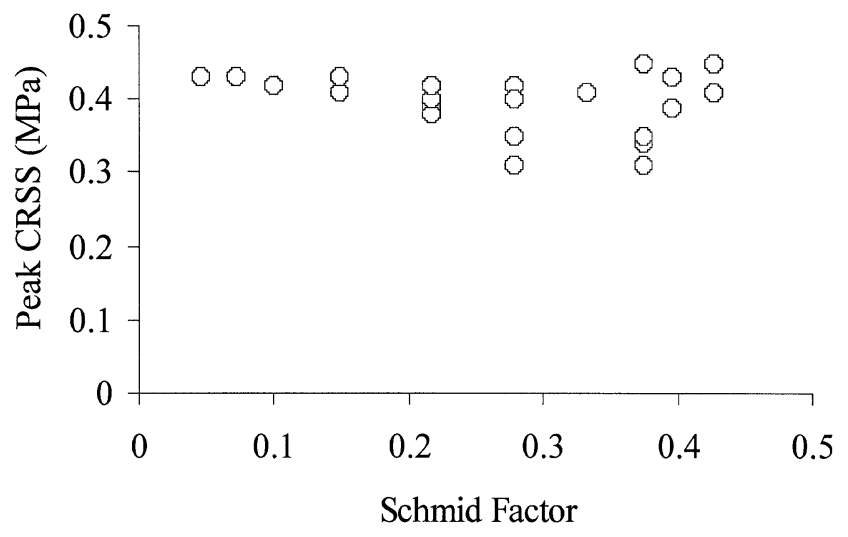

Fig. 4. Calculated peak CRSS ( at $\theta=3-70^{\circ}$ ) normalized to a constant shear strain rate on the basal slip plane of $1.0 \times 10^{-5} \mathrm{~s}^{-1}$ at $-20^{\circ} \mathrm{C}$ vs the Schmid factor $(\cos \lambda \cos \theta)$.

strain rate of $1 \times 10^{-5} \mathrm{~s}^{-1}$ at $-20^{\circ} \mathrm{C}$ vs the Schmid factor. To normalize the CRSS, the experimentally determined relationship between the peak stress, $\tau$, and the shear strain rate $\dot{\gamma} \propto \tau^{1.9}$ was used (Trickett and others, in press). If Schmid's law is obeyed, the CRSS at a constant shear strain rate will be independent of Schmid factor. Within experimental error, Figure 4 shows that this is indeed the case for ice.

That yielding of single crystals depends on stresses other than the CRSS obtained from Schmid's law has been noted in a number of materials. For example, the mechanical behavior of NiAl strongly depends on its crystallographic orientation (Takasugi and others, 1993; Mielec and others, 1997), with the calculated CRSS of stoichiometric NiAl increasing with increasing compressive stress. It was suggested that this result is due to the effect of the normal stress on the dislocation core structures. For close-packed materials, i.e. facecentered cubic (f.c.c.) and hexagonal close-packed (h.c.p.), we do not expect any effect of stresses other than the resolved shear stress, since atoms behave like hard spheres, i.e. they are incompressible. In f.c.c. metals, the multiplicity of equivalent slip systems makes it impossible to test Schmid's law over a wide range of orientations. In h.c.p. metals, in contrast, Schmid's law has been shown to apply over a large range of orientations (Honeycombe, 1968).

Typical engineering stress-strain curves for specimens with $\theta=5^{\circ}$ obtained at $-10^{\circ} \mathrm{C}$ and with various axial strain rates are shown in Figure 5. In this hard orientation, the crystals tested at $1.0 \times 10^{-4} \mathrm{~s}^{-1}$ failed by brittle fracture. Using polarized light, the cleavage cracks in the loading direction were determined to have propagated on $\{1010\}$ planes (see

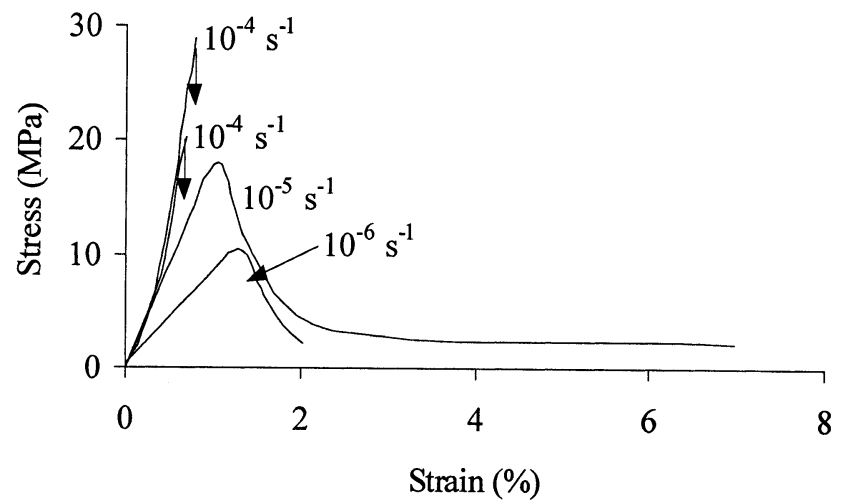

Fig. 5. Typical engineering stress-strain curves at different axial strain rates of pure-ice single crystals with $c$ axes at $5^{\circ}$ to the loading direction at $-10^{\circ} \mathrm{C}$. 
Fig. 6). The onset of cracking was observed at a strain of $0.7 \%$, corresponding to $60 \%$ of the peak stress.

Evenly spaced, well-defined slip bands were observed in these strained specimens (see Fig. 6). Thus, it was found that even at a hard orientation, i.e. with the basal plane tilted about $5^{\circ}$ from the top surface, the macroscopic plastic deformation was still produced by basal slip. Further, both the presence of the well-defined slip bands and the sharp peaks in the stress-strain curves suggest that the initial dislocation density was low (Muguruma, 1971; Brown, 1991). Note that slip lines could not be observed when testing at faster strain rates at $-10^{\circ}$ or $-20^{\circ} \mathrm{C}$.

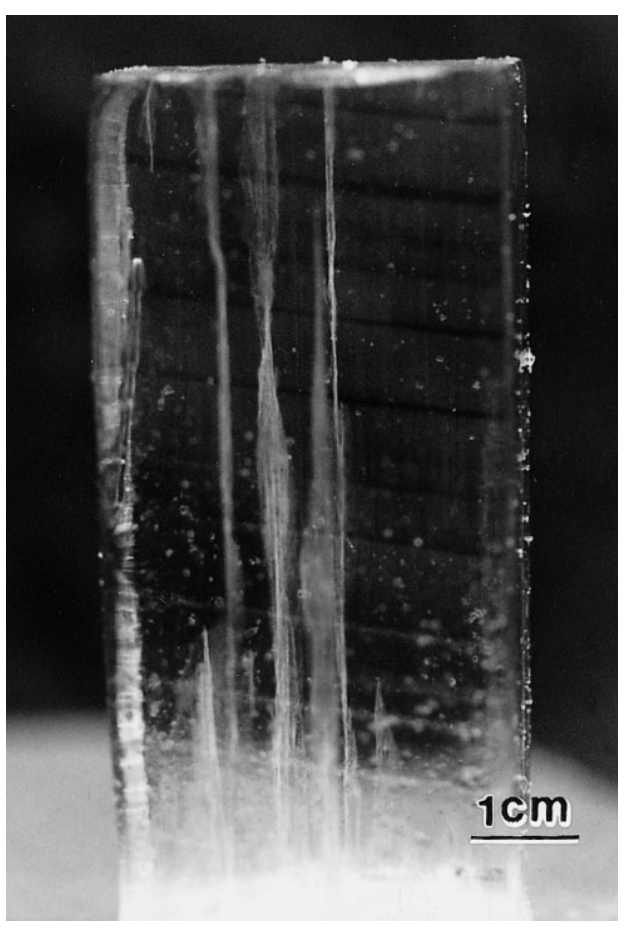

Fig. 6. Slip bands (the almost horizontal lines) in a $\theta=5^{\circ}$ specimen tested at $-10^{\circ} \mathrm{C}$ and a constant axial strain rate of $1.0 \times 10^{-6} s^{-1}$. The vertical cracks grew on $\{1010\}$ planes.

\section{GONGLUSIONS}

Stress-strain curves were obtained from laboratory-grown ice single crystals under compression at $-20^{\circ} \mathrm{C}$ and an axial strain rate of $1.0 \times 10^{-5} \mathrm{~s}^{-1}$. It was shown that the critical resolved shear stress (normalized to a constant shear strain rate of $1 \times 10^{-5} \mathrm{~s}^{-1}$ ) for basal slip obeys Schmid's law over a wide range of orientations. Slip was shown, using slip lines, to occur on basal planes.

\section{ACKNOWLEDGEMENTS}

Grant OPP-9526454 from the U.S. National Science Foundation and grant DAA-H04-96-1-0041 from the U.S. Army Research Office supported this research. The authors are grateful to one of the reviewers for pointing out the use of an incorrect equation for the shear strain.

\section{REFERENGES}

Brown, R. L. and T. Kawamura. 1991. A preliminary comparison of the properties of pure ice and sea ice single crystals. Cold Reg. Sci. Technol., 19 (3), 275-284.

Griggs, D. T. and N. E. Coles. 1954. Creep of single crystals of ice. SIPRE Rep. 11.

Higashi, A., S. Koinuma and S. Mae. 1964. Plastic yielding in ice single crystals. Jpn. 7. Appl. Phys., 3(10), 610-616.

Higashi, A., S. Koinuma and S. Mae. 1965. Bending creep of ice single crystals. Jpn. 7. Appl. Phys., 4(8), 575-582.

Higuchi, K. 1958. The etching of ice crystals. Acta Metall., 6(10), 636-642.

Hobbs, P.V. 1974. Ice physics. Oxford, Clarendon Press.

Honeycombe, R.W. K. 1968. The plastic deformation of metals. Second edition. New York, St Martin's Press.

Jones, S. J. and J.-G. Brunet. 1978. Deformation of ice single crystals close to the melting point. F. Glaciol., 21 (85), 445-455.

Jones, S. J. and J.W. Glen. 1968. The mechanical properties of single crystals of ice at low temperatures. International Association of Scientific Hydrology Publication 79 (General Assembly of Bern 1967 - Snow and Ice), 326-340.

Jones, S. J. and J. W. Glen. 1969. The mechanical properties of single crystals of pure ice. 7. Glaciol., 8(54), 463-473.

Kamb, W. B. 1961. The glide direction in ice. F. Glaciol., 3(30), 1097-1106.

Mielec, J., V. Novak, N. Zarubova and A. Gemperle. 1997. Orientation dependence of plastic deformation in NiAl single crystals. Mater. Sci. Eng., Ser. A, 234-236, 410-413.

Muguruma, J. 1969. Effects of surface condition on the mechanical properties of ice crystals. Br. 7. Appl. Phys, Ser. 2, 2D, 1517-1525.

Muguruma, J. 1971. Plasticity of ice. Bull. Jpn. Inst. Metall., 10(10), 653-666.

Nakamura, T. and S. J. Jones. 1973. Mechanical properties of impure ice crystals. In Whalley, E., S. J. Jones and L. W. Gold, eds. Physics and chemistry of ice. Ottawa, Ont., Royal Society of Canada, 365-369.

Readey, D.W. and W. D. Kingery. 1964. Plastic deformation of single crystal ice. Acta Metall., 12(2), 171-178.

Reid, C. N. 1973. Deformation geometry for material scientists. Oxford, Pergamon Press.

Schmid, E. and W. Boas. 1950. Plasticity of crystals. London, F.A. Hughes and Co. Ltd.

Steinemann, S. 1954. Results of preliminary experiments on the plasticity of ice crystals. F. Glaciol., 2(16), 404-413.

Takasugi, T., J. Kishino and S. Hanada. 1993. Stress asymmetry of stoichiometric NiAl single crystals. Acta Metall. Materialia, 41(4), 1021-1031.

Trickett, Y.L., I. Baker and P.M.S. Pradhan. In press. The effects of sulfuric acid on the mechanical properties of ice single crystals. F. Glaciol. 